\title{
Archaeological Oceanography
}

BY ROBERT D. BALLARD

\section{FOR THOUSANDS OF YEARS,} ancient mariners traversed our planet's waters; unfortunately for them, many of their ships have been lost along the way, carrying their precious cargo and the history it represents to the bottom of the sea. For hundreds of years, attempts have been made to recover their contents. In Architettura Militare by Francesco de Marchi (1490-1574), for example, a device best described as a diving bell was used in a series of attempts to raise a fleet of "pleasure galleys" from the floor of Lake Nemi, Italy, in 1531. In Treatise on Artillery by Diego Ufano in the mid-1600s, a diver wearing a roughly fashioned hood and air hose of cowhide is shown lifting a cannon from the ocean floor. But, these early efforts to recover lost cargo from sunken shipwrecks were crude and highly destructive salvage operations.

Only relatively recently have archaeologists taken an interest in such shipwrecks. Marine archaeology is a young research field with its roots deeply embedded in the technology of SCUBA (self-contained underwater breathing apparatus) diving that emerged in the early 1950s (Ballard, 2001a). However, SCUBA is limited to relatively shallow waters because compressed air becomes a deadly gas at less than 90-m depth. Recent advances in exotic gas mixtures and the development of saturation diving extend and lengthen a diver's capability. But, these advances have been primarily limited to use by the military and the professional diving communities. Although in the last few years some archaeologists have begun using exotic gas mixtures, even then they are limited to less than $100 \mathrm{~m}$ of water, which represents less than $5 \%$ of the seafloor.

The oceanographic community, however, has perfected the technology needed to work in world ocean depths that average 4,000 $\mathrm{m}$ (Ballard, 2001a). In the middle of the last century, oceanographers developed one-atmosphere, manned vehicles that were initially crude and had only the simplest manipulative capabilities. The bathyscaphe, for example, conquered the deepest ocean depth in 1960 when it descended $11,000 \mathrm{~m}$ into Challenger Deep off the Marianas Islands. But bathyscaphes had limited horizontal mobility and poor visibility. They were basically elevators to the bottom, capable only of returning shortly after they arrived.

Bathyscaphes were followed by small, highly maneuverable submersibles in the 1960s, but there was still a lack of precision manipulation and inability to carry out mapping efforts to any degree of sophistication. Though George Bass (1975) pioneered the use of this class of small submersibles to photomosaic a Roman Byzantine shipwreck off Yassi Ada, Turkey, his idea did not catch on within the marine archaeology community, which preferred the dexterity of human hands to excavate ancient shipwrecks.

While marine archaeologists continued to rely upon divers to carry out their work, marine geologists were perfecting the use of manned submersibles. At first, they, like marine archaeologists, concentrated on the shallow depths of the continental shelf. Francis Shepard (1964) and his students at Scripps Institution of Oceanography began exploring nearby submarine canyons using SCUBA diving techniques but later turned to Jacques Cousteau's Souscoup to explore their deeper depths. Like the bathyscaphe before it, Souscoup was used primarily as an observational platform and had limited manipulation and crude mapping capabilities.

A major breakthrough program 
in marine geology-one that would also ultimately have a major impact on marine archaeology-was Project FAMOUS, the 1974 French-American Mid-Ocean Undersea Study (Ballard, 2001a). FAMOUS marked the first manned exploration of the mid-ocean ridge and the first use of manned submersibles for comprehensive mapping of complex geologic terrain. Prior to this program, submersibles had been used as exploratory tools, but due to the lack of precise knowledge about the terrain in which they were operating as well as the lack of accurate navigation, their use had been ineffectual, diminishing their value in mainstream oceanographic programs. During Project FAMOUS, manned submersibles were used in a more surgical fashion.

Before the three FAMOUS submersibles began their dives, the region to be studied-the rift valley of the MidAtlantic Ridge-was intensely surveyed using a broad array of mapping devices, including multi-narrowbeam sonar systems, side-scan sonars, and a variety of imaging systems. By the time the submersibles were deployed, the scientists had acquired detailed topographic maps of the rift valley and developed significant understanding of its geology. The submersibles were able to work within this accurate database, examining specific targets of importance to the scientific team. Even so, their mapping technology and acoustic navigation system limited their resolving power to a few meters at best, clearly short of the mapping precision of marine archaeologists, who were accustomed to centimeter accuracy. And, once again, the manned submersible manipulators were crude when compared to the dexterity of a diver's hands.

In the late 1980s, it became apparent to some oceanographers that much manned submersible work could be conducted by more efficient, cost-effective research platforms. To reach $4,000 \mathrm{~m}$, scientists spend two and half hours in the morning to make their descent to the bottom, followed at the end of the day with a similar ascent to the surface. Thus, they have only three or so hours to work on the bottom, typically covering one nautical mile of underwater terrain.

The advent of fiber-optic cables, also in the 1980s, made it possible to develop a remotely operated vehicle (ROV) that could transmit high-quality imagery to the surface and create "tele-presence" on the ship's deck. With this technological leap forward, scientists were able to deploy an ROV for long periods on the bottom while controlling its operation onboard ship. Critical to the success of this technology, however, was the ability to precisely control both the surface ship and the ROV thousands of meters below. Control of the ship was made possible through the development of dynamic positioning systems coupled with the use of GPS navigation. Precise control of the ROV was more difficult because, unlike GPS that had a broad user base, there was little interest in such precise vehicle control.

In the early 1990s, major new technology closed the gap between the marine geologist and the marine archaeologist when engineers interested in precision control of ROVs developed the SHARPS tracking system (Ballard, 2001a). The fact that this system was wired severely limited its initial use to test tanks or shallow water. What was important about the SHARPS system was its tracking precision, measured in centimeters every few seconds, which made it possible to place the vehicle in automated "closedloop" control, driven by a computer instead of a human operator. A few years later, SHARPS was replaced by a wireless system called EXACT, which now makes it possible to precisely control an ROV in any water depth, including down to 6,000 m, now a common ROV operating depth-a depth that encompasses $98 \%$ of the world's ocean floor. Equally important, scientists not only know where the ROV is every few seconds, they know the position of its various sensors, sonars, and cameras.

\section{HAMILTON AND SCOURGE PROJECT}

The first major application of this integrated technology for marine archaeological purposes was the 1990 survey of the Hamilton and Scourge in Lake Ontario. These two American ships sank in a violent storm during the War of 1812. They were identified in 1975 and later given to the Canadian city of Hamilton by President Carter; the city wanted to know their precise condition and whether these ships should be raised or left where they were.

Answering these questions required a detailed survey of the ships to a precision not previously possible. Installed on a barge anchored over the wreck site, the SHARPS system tracked ROV Jason operating in "closed-loop" control to record data from which detailed optical and acoustical mosaics and threedimensional images were constructed.

About the same time that this cooperative program between marine archaeologists and oceanographers accomplished these advances in precision 
Over the next nine years, nine Roman trading ships (Figure 1) dating from the first century BCE to the fourth century $\mathrm{CE}$ were found within this corridor of ancient debris as well as two long lines of amphorae that were obviously thrown overboard by ships hoping to save themselves in storms by jettisoning their cargo (Ballard, 1998; Ballard et al., 2000).

Following this success, additional Figure 1. Hercules ROV grasping amphora from first century CE shipwreck at Skerki Bank.

shallow-water mapping, new deep-water discoveries occurred that would have a profound impact on the field of marine archaeology. The discovery of RMS Titanic marked the beginning. Prior to its discovery, little thought was given to the fate of shipwrecks in the deep sea, other than recent lost Russian and US submarines. What Titanic and its thousands of artifacts revealed was that total darkness, freezing temperatures, and extreme pressures result in a preserving environment. That environment, coupled with slow sedimentation rates and the absence of human intrusion, meant the deep sea was an ideal place to look for human history. Marine archaeologists quickly conceded that the deep ocean was a better preserving environment than shallow water, but they questioned whether it contained a significant number of notable shipwrecks.

Although ancient literature spoke of the ancient mariners' bravery and willingness to travel great distance

ROBERT D. BALLARD (ballard@gso.uri. edu) is Professor and Director, Institute for Archaeological Oceanography, Graduate School of Oceanography, University of Rhode Island, Narragansett, RI, USA. from shore, few modern scholars believed these accounts. Those doubts, however, began to be revisited when exploratory programs in the central Mediterranean revealed ancient shipwrecks far from shore.

\section{SKERKI BANK PROJECT}

The first such major program was conducted in 1988 along a proposed deepwater trade route between ancient Carthage and the Roman seaport of Ostia. Called the Tyrenennian Sea, this body of water reaches depths of 4,000 m. The expedition team looked first along the shorter trade routes connecting Sardinia to Tunisia, Tunisia to Sicily, Sardinia to Sicily, and Sicily to Italy, but with no success. They then began to explore the less-probable and longer trade route connecting Tunisia to Rome. Traveling along an east-west line in the Straits of Sicily north of Skerki Bank, they began to spot isolated amphorae lying on the soft sediment surface at a depth of 1,000 m. After an extensive mapping effort, a seven-kilometer-long corridor of amphorae was delineated, followed by a random sampling effort that revealed their ages to span six centuries of history. expeditions were conducted in search of more deepwater trade routes. In 1999, an expedition working off the Middle East located two Phoenician ships, each carrying a large cargo of wine on their way from the Levant to either Egypt or Carthage (Figure 2) (Ballard, 2001b; Ballard et al., 2002).

In both the Straits of Sicily and off the Middle East, wood-boring organisms had attacked the ancient shipwrecks, removing any exposed wood. For hundreds of millions of years, trees and other wooden debris have been carried down rivers in storms and transported out to sea where they sank to the bottom. Given this source of nutrients to the nutrient-starved deep seafloor, mollusks evolved into wood-boring organisms. Because the deep sea is provided with a constant source of dissolved oxygen due to the planet's polar circulation patterns, wood-boring organisms are found throughout the world's ocean anywhere there has been a constant source of wood.

\section{BLACK SEA PROJECT}

Wood-boring organisms are present in marginal seas, like the Mediterranean, that have connections to the world's ocean that permit deepwater circulation. In the case of the Black Sea, however, no such deepwater connection exists. The 
Black Sea's deep saline waters are isolated from the deep oxygenated waters of the Mediterranean by a shallow-water sill connecting the Aegean Sea with the Bosporus. This isolation has lead to the depletion of dissolved oxygen at the bottom of the Black Sea and the creation of anoxic conditions, causing scientists to predict that the Black Sea would be an ideal place to look for highly preserved ancient wooden ships (Bascom, 1976). During the Cold War, western researchers could not work freely within the Black Sea. Beginning in 2000, however, scientists were able to explore its deeper waters for the first time in search of highly preserved wrecks. As a result of that effort, four ancient wooden shipwrecks have been discovered, all from the Byzantine period (Ballard, 2001b; Ballard et al., 2001). Three of those ships were located above the anoxic layer (Figure 3 ) in water depths of 90 to $100 \mathrm{~m}$, while the fourth was situated within the anoxic layer at a depth of $320 \mathrm{~m}$.

Wood was present in large quantities throughout a broad depth range, even above the anoxic layer to as shallow as $80 \mathrm{~m}$. The most well-preserved ship, however, was the deeper one within the anoxic layer. The first sign of the ship was when the ROV came in on its wooden mast standing upright, 11-m high. Exposed frames, stanchions, and what appeared to be a rudder support and sternpost were clearly visible.

The shipwrecks lying above the anoxic layer had numerous exposed wooden members, although the ships had splayed open, forming a large mound of ampho- rae. Unlike the deeper shipwreck that had come to rest in soft ooze, penetrating the bottom until the deck was at the mud line, the shallower shipwrecks had landed on a much harder, eroded surface and barely penetrated the bottom.

\section{FUTURE CONSIDERATIONS}

Despite this proof of potential, there was a need for sophisticated deepwater excavation technology that would meet archaeological standards. Though salvagers have developed varying levels of recovery and mapping technologieswith the best example centered on the gold rush-era wreck of Central America off Charleston, SC-they are not considered archaeologically sound.

Marine archaeologists have made some limited efforts to conduct experiTanit, protector of Phoenician seafarers, is the Iron Age successor of the leading Canaanite goddesses Astarte and "Ashera of the Sea." 


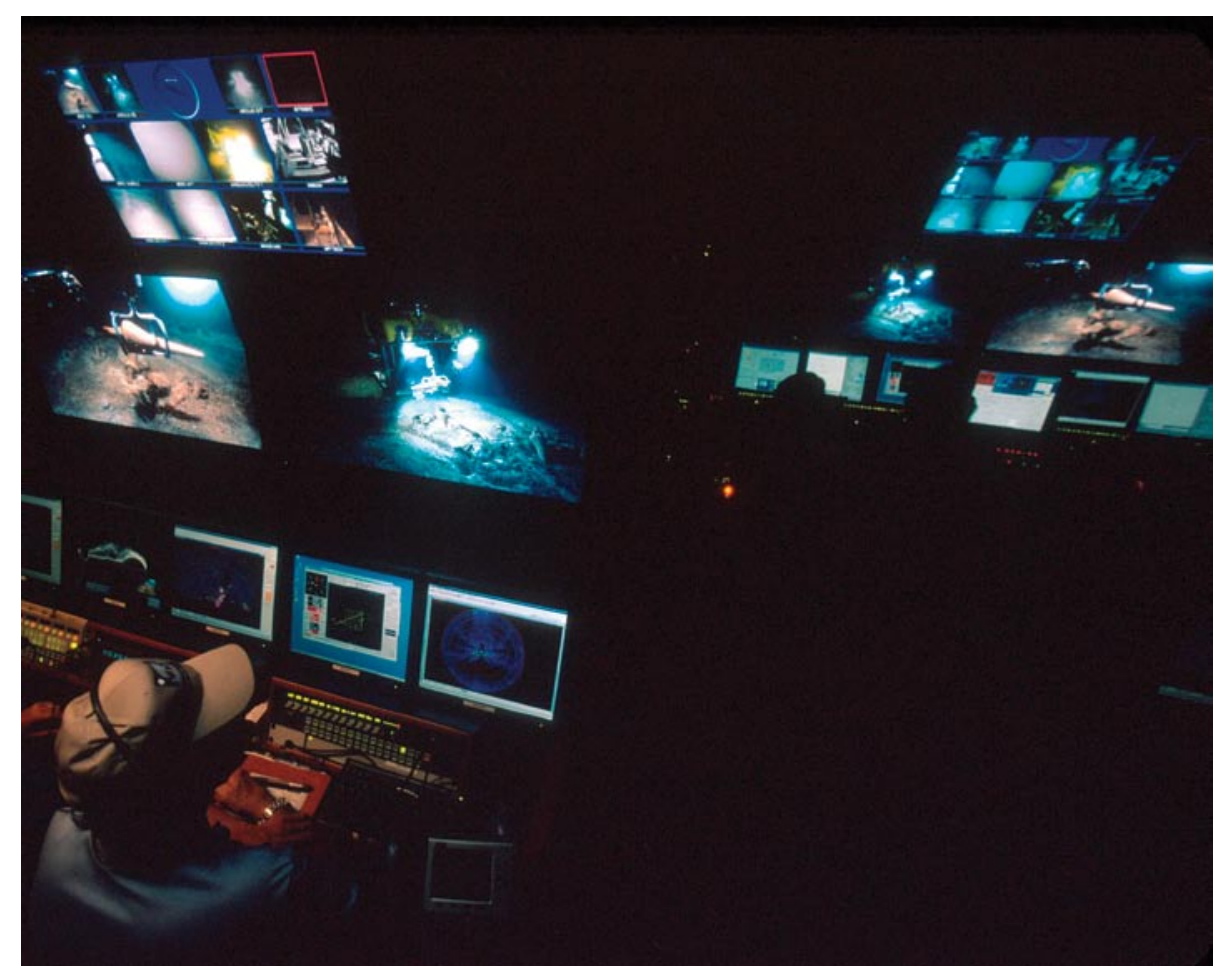

Figure 3. Shipboard control van during the recovery of ancient artifacts from Byzantine shipwreck off Sinop, Turkey. Photo credit: David McLain

mental excavations in the deep sea (Ballard et al., 2000). During the Skerki Bank project, for example, the US Navy nuclear submarine NR-1 was outfitted with a mud-pumping system, but the submarine's large mechanical arm lacked precision control and further excavation efforts were terminated. ROV Jason used a much smaller excavating device, but the deep-sea mud proved challenging, and only a limited amount of mud was removed before the ROV was diverted to survey several additional Roman shipwrecks discovered near the end of the expedition.

Based upon these early efforts at excavating ancient shipwrecks in the deep sea, the Institute for Exploration in collaboration with the Institute for Archaeological Oceanography developed a new ROV called Hercules (Figure 4) to
To the world of marine archaeology, this sum is prohibitively expensive and even more prohibitive when compared to archaeological programs carried out on land. The traditional archaeological community and its traditional funding sources are unlikely to allocate scare resources to study deep-sea shipwrecks. But, there is no reason why archaeological oceanography could not be supported by the same sources that fund other oceanographic research.

It is important to point out that oceanography is not a separate discipline, as are physics, chemistry, or geology; rather, it is an arena in which these disciplines are bonded by common needs, such as for unique facilities that are required to carry out these separate lines of research. It is common for the various disciplines to work together on oceanographic field programs, similar to the way multidisciplinary programs are carried out on land or in outer space. Oceanographers come from all fields of science and engineering, and the list could easily be expanded to include the social sciences of maritime history, archaeology, and anthropology.

More importantly, oceanography is a young enough science to be inclusive, and its practitioners are accustomed to accepting new disciplines into the fold. The history of marine geology is an excellent example. Initiated in the 1930s, it was dominated for some time by sedimentologists concentrating on the continental margins of the world. But, the evolving theory of plate tectonics in the 1960s took the earth sciences into the deeper ocean basins, bringing in petrologists, volcanologists, and structural geologists. The discovery of hydrothermal vents on the mid-ocean 


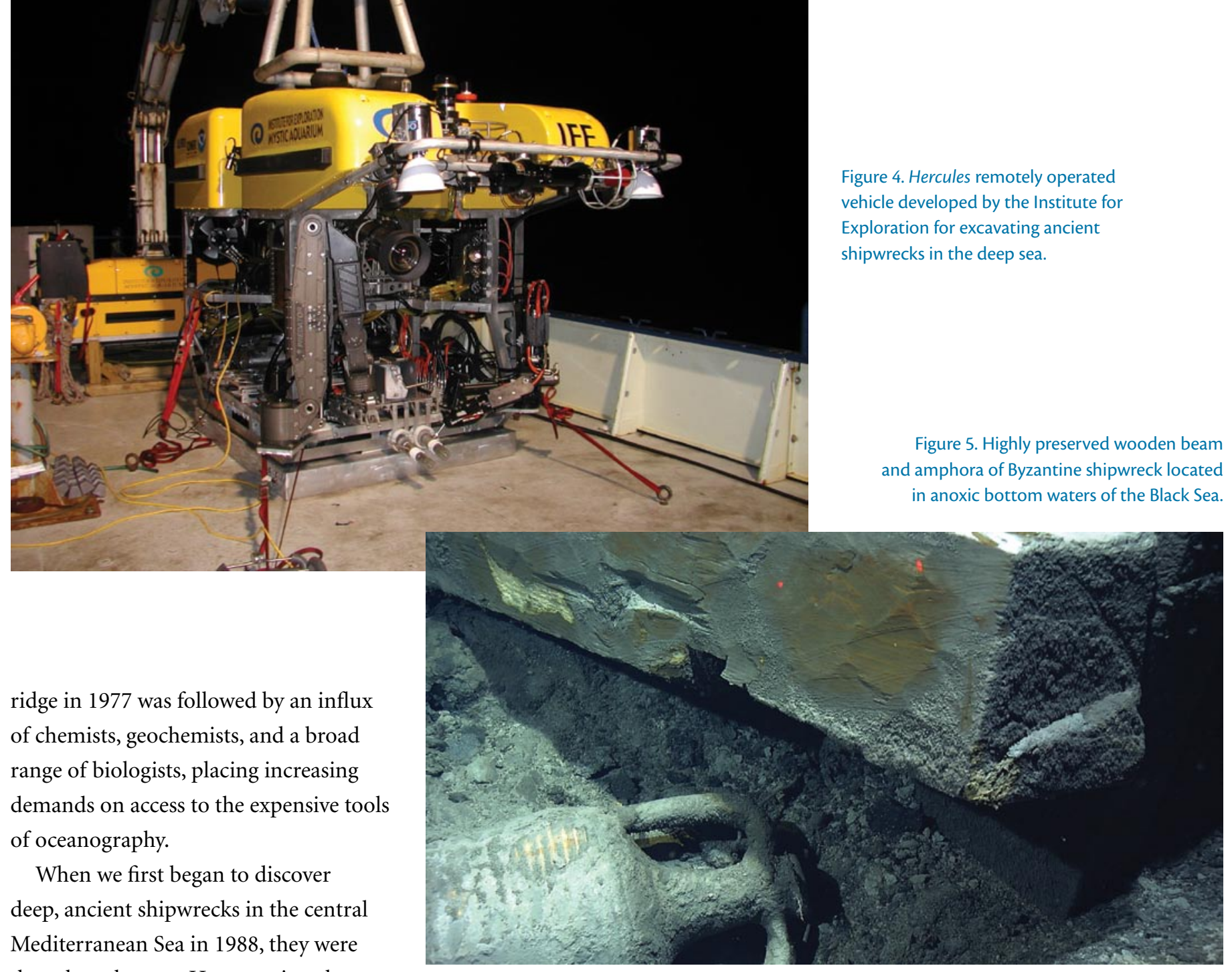
thought to be rare. However, in subsequent years, more and more ancient shipwrecks were found in other deepwater locations. More recently, professional salvage companies have obtained the necessary technology to carry out commercial recovery programs.

It is increasingly clear that the deep sea could be of great importance to the social fields of archaeology, anthropology, history, and art, to name a few. But how can this interest turn into a meaningful and viable research program? Though the term archaeological oceanography may sound like the former is subordinate to the latter, that is not the case: just as a geological oceanographer is a geologist working in the ocean, an archaeological oceanographer is an archaeologist working in the ocean. Perhaps the time has come for

oceanography to accept a new discipline into the fold.

It is encouraging to see recent willingness on the part of the leadership of the National Oceanic and Atmospheric Administration's Ocean Exploration Program to support the budding field of archaeological oceanography. We hope that other federal funding agencies follow suit. 㞎

\section{REFERENCES}

Ballard, R.D. 1998. High-tech search for Roman shipwrecks. National Geographic 193(4):32-41.

Ballard, R.D., A.M. McCann, D. Yoerger, L. Whitcomb, D. Mindell, J. Oleson, H. Singh, B. Foley, J. Adams, D. Piechota, and C. Giangrande. 2000. The discovery of ancient history in the deep sea using advanced deep submergence technology. Deep-Sea Research Part I 47:1,591-1,620.
Ballard, R.D. 2001a. Maritime archaeology. Pp. 16751681 in Encyclopedia of Ocean Sciences, Vol. 3, J.H. Steele, K. Turekian, and S.A. Thorpe, eds, Academic Press.

Ballard, R.D. 2001b. Ancient Ashkelon. National Geographic 199(1):91-93.

Ballard, R.D., F.T. Hiebert, D.F. Coleman, C. Ward, J. Smith, K. Willis, B. Foley, K. Croff, C. Major, and F. Torre. 2001, Deepwater Archaeology of the Black Sea: The 2000 Season at Sinop, Turkey. American Journal of Archeology 105(4):607-623.

Ballard, R.D., L.E. Stager, D. Master, D. Yoerger, D. Mindell, L. Whitcomb, H. Singh, and D. Piechota. 2002. Iron Age shipwrecks in deep water off Ashkelon, Israel. American Institute of Archaeology 106(1):151-168.

Bascom, W. 1976. Deep Water, Ancient Ships: The Treasure Vault of the Mediterranean. Doubleday Books, 226 pp.

Bass, G. F. 1975. Archaeology Beneath the Sea. Walker and Co., New York, 238 pp.

Shepard, F.P., J.R. Curray, D.L. Inman, E.A. Murray, E.L. Winterer, and R.F. Dill. 1964. Submarine geology by diving saucer. Science 145:1,042-1,046. 